\title{
Solar potential calculation at city and district levels
}

\author{
E. Caamaño-Martin ${ }^{1}$, E. Higueras ${ }^{1}$, F. J. Neila ${ }^{1}$, I. Useros ${ }^{1}$, \\ D. Masa-Bote ${ }^{1}$, F. Tortora ${ }^{1}$, S. Díaz-Palacios ${ }^{1}$, X. Marrero ${ }^{2}$,

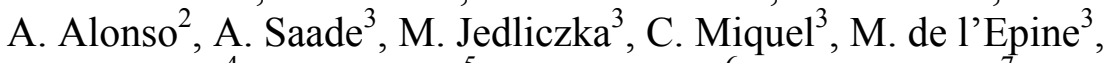 \\ E. Willdbrett ${ }^{4}$, E. Kjellsson ${ }^{5}$, A. Cornander ${ }^{6} \&$ J. Fernandes ${ }^{7}$ \\ ${ }^{1}$ Technical University of Madrid, Spain \\ ${ }^{2}$ City of Vitoria-Gasteiz, Spain \\ ${ }^{3}$ HESPUL, France \\ ${ }^{4}$ Local Energy Agency of the Grand Lyon, France \\ ${ }^{5}$ University of Lund, Sweden \\ ${ }^{6}$ Skane Energy Agency, Sweden \\ ${ }^{7}$ Lisboa Enova, Portugal
}

\begin{abstract}
Several cities worked together through the European cooperation project POLIS on the identification of active and passive solar potential. Different studies were set up within a specific framework, using different methodologies in order to reach the shared goal. The following paper presents initiatives in Malmö (Sweden), Vitoria-Gasteiz (Spain), Lyon (France) and Lisbon (Portugal). There are 2 main objectives for these initiatives. The first goal is to guide the development of solar energy on a large scale (ex: city level) by identifying the urban areas where solar energy could be easily implemented or where energy needs are very high. The second goal aims to bring information to inhabitants and building owners on the potential of their roof to encourage them to invest in solar. Providing this information requires detailed calculations and results readily understandable by the beneficiaries. It is usually implemented at the level of a district previously identified.

Keywords: solar potential, photovoltaic, solar thermal, passive solar energy supply, urban planning.
\end{abstract}




\section{Introduction}

In recent years, many European cities have engaged in the identification of solar potentials. The aim of these calculations can be very different from one project to another and sometimes the objectives are not previously defined. Within the framework of a cooperation project, six European cities (Munich in Germany, Lisbon in Portugal, Paris and Lyon in France, Vitoria-Gasteiz in Spain and Malmö in Sweden) have committed to long-term strategies to integrate solar energy at an urban level. These strategies are consistent with existing $\mathrm{CO}_{2}$ mitigation targets in Solar Action Plans embedded in local planning processes.

Although the project cities have different climates, and hence different solar strategies, a common objective of steering the future development of solar energy with respect to urban planning is shared. This goal is to be achieved through the assessment of existing climate strategies and targets at city level, the evaluation of solar potential in city areas, the development of solar targets and the definition of possible measures in diverse planning areas connected to general renewable energy targets. Only a strategic approach by the municipality can enhance the increasing integration of small-scale, decentralized energy applications into the built environment.

The Solar Action Plans have been developed taking into account the local context in terms of energy supply, user behaviour, urban structures, building typologies, existing solar actions and measures, urban planning practices with solar requirements, etc. These Plans have been set up by Local Working Groups composed of municipalities and technical partners of the project. Each city has developed long-term solar targets, as well as having identified interest focus areas, stakeholders for the implementation of solar energy in connection with urban approaches and, finally, short-term measures to support the uptake of solar energy and reach the proposed targets.

Of all the short-term measures identified, some concern identification of solar potential on a large scale and the definition of priorities:

- Potential Study in Sege Park, Malmö.

- Assessment of the Detailed Solar Potential of Lakua district, Vitoria-Gasteiz.

- Photovoltaic Solar Cadastre of Sainte Blandine district, Lyon.

- Assessment of the General Solar Potential of Vitoria-Gasteiz, Spain.

- Evaluation of solar potential in Lisbon.

\section{Precise solar potential calculation at the district level}

\subsection{Potential Study in Sege Park, Malmö, Sweden}

Sege Park is an area in Malmö with buildings undergoing retrofitting measures and a new development zone with a "green" profile - the district has planning measures and opportunities for using solar energy as well as other renewable energy sources. Malmö city wishes to promote the integration of solar energy at an urban level and has determined targets for solar energy applications. 
This study consists of developing a methodology for assessing the detailed solar potential of buildings in Malmö. The result will be made available to the public on-line, and the methodology made available to other cities/countries with similar legislation. Today, all buildings in Malmö can be analysed photogrammetrically with the program ESPA Systems, where roof geometries can be digitised with an accuracy of better than $10 \mathrm{~cm}$. Roof geometries and the building footprints from the detailed municipal primary map can then be used in conjunction with a digital elevation model (DEM) to produce a digital surface model (DSM) as raster data, or 3D vector data for input into AutoCAD or SketchUp based applications for solar potential analysis.

Possible tools are tested, developed and validated through the analysis of the Sege Park area. As a result, a 3D analysis of the buildings will be conducted and the potential for solar energy will be calculated, including potential reductions from obstacles and shading.

One method, which is ready for use, is to make manual calculations of the annual irradiation on the building envelopes. Here many tools are available including PVSUN, but also the free tool PVGIS from the JRC (EU Joint Research Centre in Ispra, Italy). PVGIS gives quick results for single surfaces and includes climate data for Europe and Africa. However, this tool is really only adapted for a small number of buildings, as each surface must be calculated separately. It may also be difficult to quantify shading from the surrounding buildings, obstacles on the roof and vegetation.

In order to create a tool which is able to systematically produce comparable results for different areas, both within the city but also on a national or even global level, great care must be taken when defining the input data sets. The tool should use readily available $3 \mathrm{D}$ townscape data and not rely on highly processed and unspecified data sets.

The work so far has shown that the type and quality of input data is of utmost importance, particularly for building geometries. The decision must be made to work with raster or vector data. There are pros and cons for each: solar ray tracing, for shading analysis due to adjacent buildings and vegetation, is best performed on vector data. However, in order to apply the shading factor over the roof area, some grid analysis must be performed. On the other hand, applying a grid analysis for large areas at a sufficient resolution will create large datasets that require great computing power, if the analysis cannot be restricted to roof area pixels only.

The tools that have been tested so far are both raster and vector based. In Sweden a new vector based tool has been developed during 2011, SEES, Solar Energy from Existing Structures. So far the current version of the program can only be used for a small area. The development of the program is still ongoing.

Another tool tested is the Autodesk Ecotect Analysis program, which has the features for calculation of solar irradiation on large areas, including shadings. Evaluation vis à vis input data required, as well as the accuracy of calculation results are ongoing. 


\subsection{Assessment of the detailed solar potential of Lakua district, Vitoria-Gasteiz, Spain}

Vitoria-Gasteiz has signed several commitments related to energy and sustainability. In addition, due to the signing of the "Covenant of Mayors" document in 2009 , the city has to adapt its targets to the new commitment of going beyond the $20 \% \mathrm{CO}_{2}$ emission reduction and the promotion of renewable energies. For this reason, Vitoria-Gasteiz is currently working on a new "Fight against Climate Change Plan", a "Climate Change Adaptation Strategy" and an "Energetic Ordinance" where new targets and actions will be set to reduce $\mathrm{CO}_{2}$ emissions and promote renewable energies. A detailed study to quantify the urban solar potential is considered of highest priority within the Solar Action Plan in order to identify the realistic possibilities of solar energy use in VitoriaGasteiz.

Besides local requirements related to solar passive and active technologies, national requirements (Technical Building Code) must be considered also in the solar potential assessment. A methodology combining both types of requirements does not exist yet. The district of Lakua (north of the city, area of 376 Ha.) is one of the priority areas defined in the Solar Action Plan.

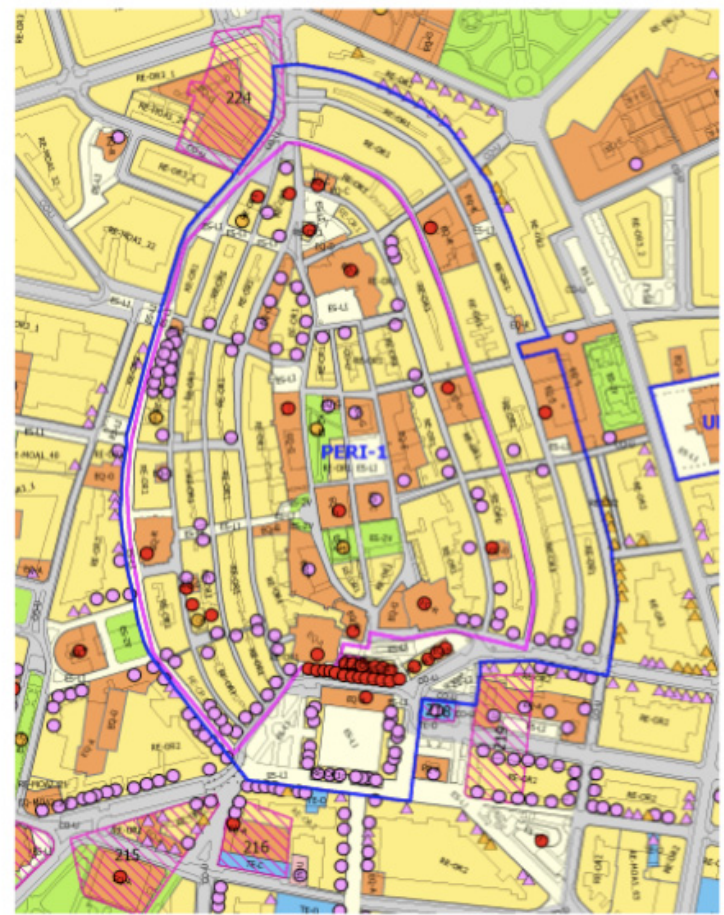

Figure 1: $\quad$ Vitoria-Gasteiz Zoning Map. Protected buildings. 
The methodology initially developed at a district scale for the Lakua residential district has been adapted to the Geographical Information System (GIS) used in the Municipality of Vitoria-Gasteiz. This allows multicriteria analyses to be carried out in order to assess the urban solar potential. The GIS based methodology for identification of solar potential gives the possibility to study the relationship between urban solar potential and socio-economical factors.

A GIS cartography has been provided by the municipality of Vitoria-Gasteiz. This cartography incorporates the information contained in the Urban Development Plan, such as historical protected buildings, ordinances applicable in each urban plot, etc. As a first step, all protected buildings have been excluded from the calculations and buildings surrounding them were individually analyzed. The buildings ages were incorporated in the spatial database. Another classification is applied based on legislation applicable at the year of construction and typical structural systems used.

3D CAD data of buildings were provided by the Municipality of VitoriaGasteiz. It brought information at lot or building scale, but often incomplete (constructive elements not defined or incomplete). Analysis of individual constructive elements has required developing specific high-quality cartography with the aid of aerial photographs. These data have been imported to GIS maps, identifying each building construction element (roofs and facades) of the buildings as an independent unit with associated information: dimensions, azimuth and slope.

\subsubsection{Calculation of passive solar potential}

A climatic analysis is undertaken in order to identify the solar radiation needs (under-heated period).

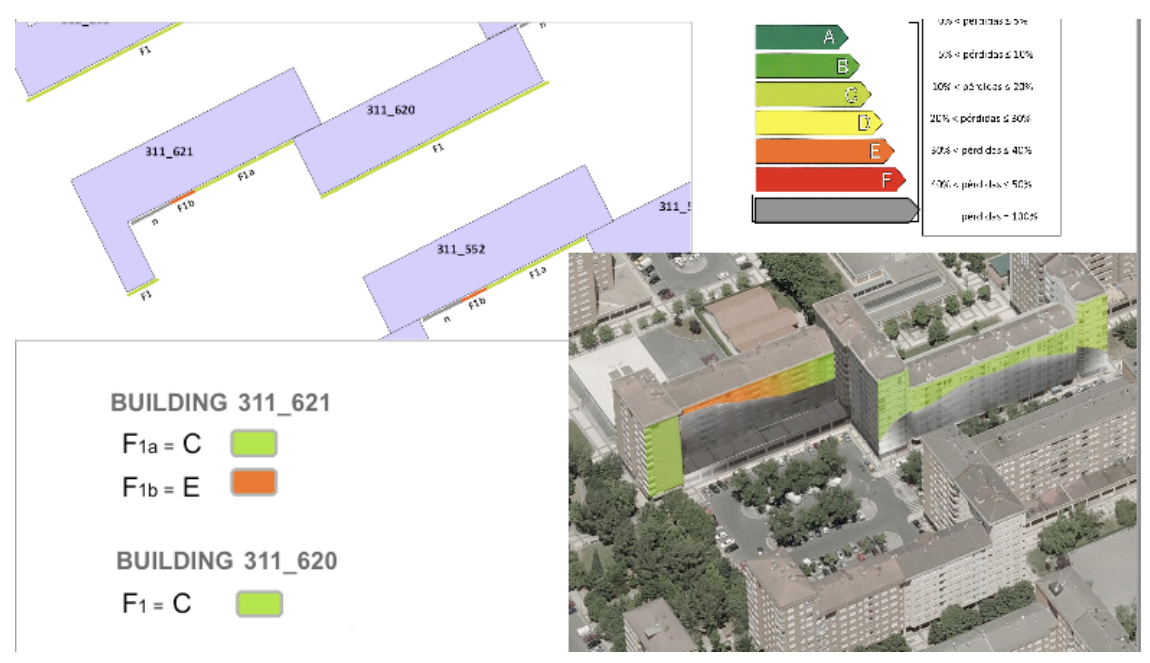

Figure 2: Solar passive potential categorisation. 
Solar resource assessment has been done considering:

- Only direct solar radiation component to be considered. Only façades are analysed.

- Solar radiation incident on the façades during the under-heated period is computed (IES-UPM software: validated models).

- Solar radiation results: losses are compared to an optimal façade (South oriented, free from shadows during 4 hours centred around solar noon in the winter solstice).

- Maximum acceptable losses: 40\% (Spanish National Building Code)

- Shadow losses during 4-hour period, from 10 AM to 2 PM are computed, in order to identify the acceptable façades fraction.

The calculation led to solar potential categorization through 6 colour codes depending on solar radiation losses relative to the optimal facades.

\subsubsection{Active solar potential}

Different types of roof typologies (flat/tilted with concrete framework, light tilted, ventilated tilted) and different typologies of façade (brick, light, prefabricated concrete) were identified.

Structural loads (permanent \& overloads) are calculated in order to determine construction elements suitability for typical active solar components (PV modules/solar collectors).

Annual global solar radiation incident on the constructive elements is calculated considering maximum acceptable losses: 40\% (National Technical Building Code: active solar systems). Annual shadow losses are calculated in order to identify the acceptable constructive elements.

\subsubsection{Solar thermal}

Firstly, solar thermal calculations were made considering:

- Assessment of domestic hot water needs (Technical Building Code and VitoriaGasteiz Energy Ordinance draft)

- Assessment of heating needs through facades and roof constructive elements (degrees-day method)

- Use of Klein \& Beckman f-chart method (overheating analysis included).

A second step produced a solar potential categorisation. 2 codes, depending on the suitability of construction element: Green suitable; Gray not suitable. Suitable construction elements also include information about number of collectors needed to cover $50 \%$ of DHW needs and number of collectors to cover $35 \%$ of DHW + heating needs.

\subsubsection{Solar photovoltaic}

A PV potential categorization was done considering 6 categories depending on solar resource losses, relative to an optimal surface (south oriented, $32^{\circ}$ tilted).

\subsection{Photovoltaic Solar Cadastre of Sainte Blandine district, Lyon, France}

A large urban regeneration project called Lyon Confluence (150 hectares) is in the city's centre; this project will extend the city centre by means of high-quality 


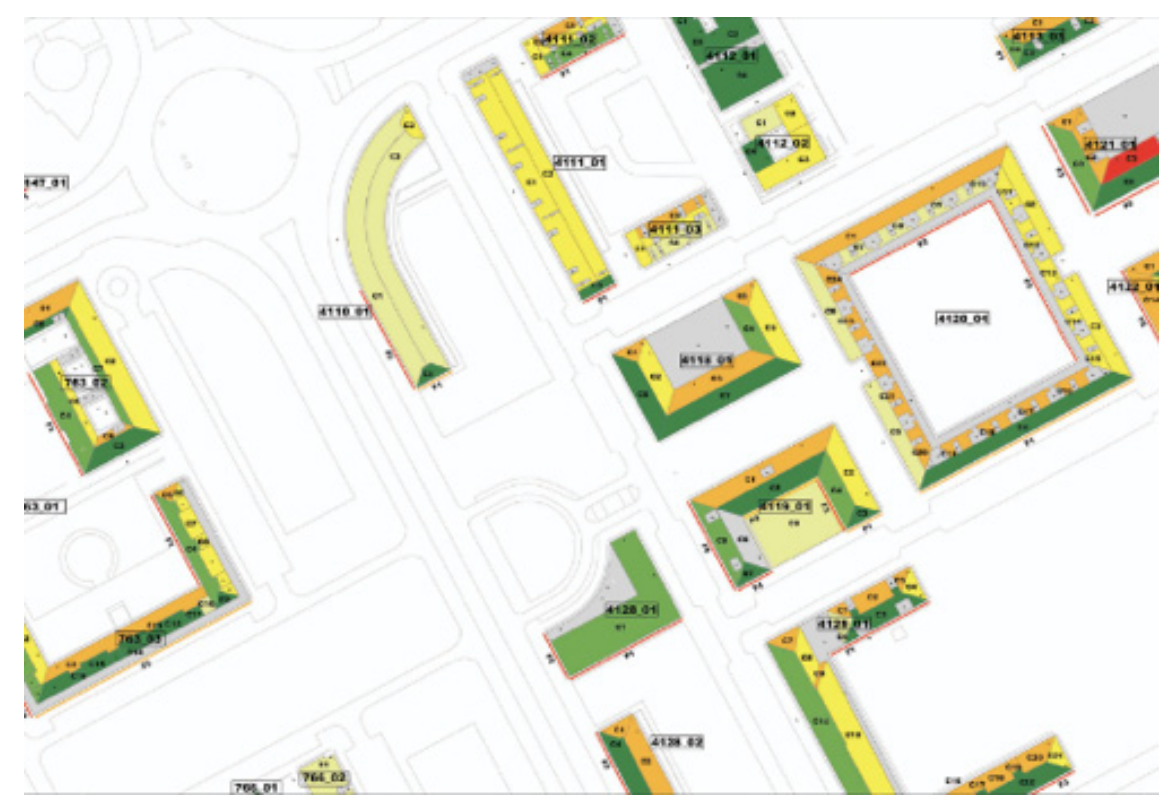

Figure 3: $\quad$ PV potential categorization.

development projects that meet stringent quality criteria in terms of urban planning, architecture, environmental impact and landscaping. In 2004 an EUfunded Concerto program called "Lyon Confluence" was set up on this area with the aim of introducing energy considerations (consumption and renewable production) in the first phases of the urban planning process. This initiative has recently been extended to and enhanced the urban rehabilitation of an area called Sainte Blandine, neighbouring the confluence area. Within the rehabilitation program of this old city district, energy aspects and experiences on the rehabilitation of an historical area are two aspects of most interest for the municipality of Lyon.

A solar potential study has been undertaken by HESPUL in order to calculate the potential of each roof of the city. A 3D map of the district has been produced by an urban management and architecture office URBANIS. This 3D visual served as a basis for a solar projection and an evaluation of the shaded areas. The solar projection was done with "Sketchup" software.

The next step was the evaluation of potential obstructions on the roofs. Aerial pictures were necessary. Depending on the obstruction, some of the roofs were excluded from the calculations.

As the area is considered globally homogenous from an architectural point of view, a standard roof slope was chosen for calculations.

Only roofs oriented between $90^{\circ}$ east and $90^{\circ}$ west were considered. A simulation of the electricity produced was then completed done with PV Syst software. This simulation helped to determine the losses due to these criteria. 

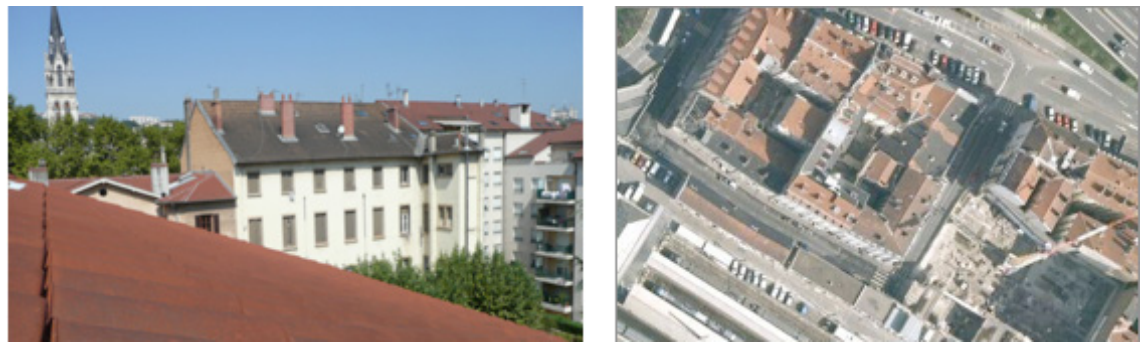

Figure 4: $\quad$ Pictures of the Sainte Blandine district.

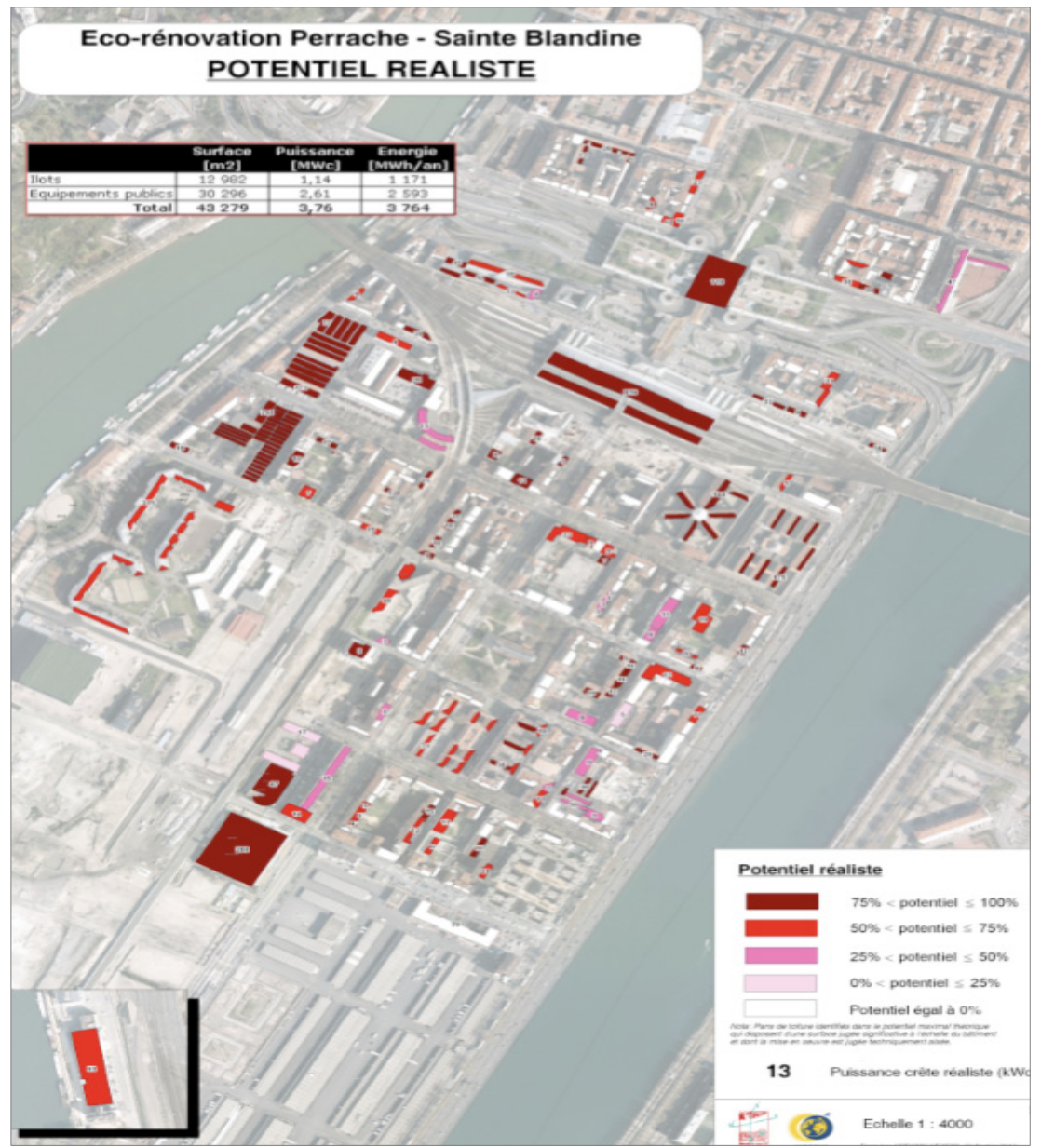

Figure 5: $\quad$ Map presenting PV potential results on the entire district. 
A final criterion was applied to reach a "realistic" potential. Only surfaces of at least $50 \mathrm{~m}^{2}$ were considered. As most of the Sainte Blandine area is occupied by buildings managed by a strata title, the decision to invest in solar energies on roofs can be very long and complex. Therefore, setting up of a PV project of less than $5 \mathrm{kWp}$ is time consuming with very limited results.

The final results of the study showed:

- 1,14 MWp for housing buildings.

- 2,61 MWp for other buildings (school, train station...).

The results are available on the Climat Plan Blog of Lyon Conurbation through an interactive map. Inhabitants of the Sainte Blandine District and final users of the buildings can access information concerning their roof by clicking on the online map: estimation of the PV power and production, surface of their roof and economical incentives are indicated. More general information regarding PV technology and its legal framework in France is also available.

\section{Identification of solar potential at city level}

\subsection{Assessment of the general solar potential of Vitoria-Gasteiz, Spain}

This assessment complements the detailed methodology with a complete-city level approach. In order to calculate the solar potential three different cartography sources have been used simultaneously: a Digital Elevation Model (DEM) obtained from LIDAR data, a local CAD cartography incorporating the detailed definition of the roofs and the local zoning maps used to identify protected areas, building use and age.

The global annual radiation incident on the roofs has been calculated by means of GIS software and the results obtained are converted into a discrete quantity for each roof part through statistical calculations (mean value and standard deviation). Once the radiation incident has been calculated, different filters have been applied to identify the roof parts which are actually suitable for solar energy panels. Some of these filters are surface available, building protection and structural conditions.

The availability of LIDAR data has been a key factor to create a Digital Elevation Model of the city. The use of GIS software for Solar Radiation Calculation using the DEM avoids a case by case study. This combined with the cartography incorporating a high detailed definition of the roof parts has been translated into a detailed solar potential map of the whole city.

\subsection{Evaluation of solar potential in Lisbon, Portugal}

Lisbon is without any doubt the sunniest capital in Europe. The question is: Is it also the capital that presents the highest potential to take advantageous of this resource? The built environment is obviously to address in this question and for this goal, the Lisbon Energy Agency - Lisboa E-Nova, in cooperation with the Lisbon Municipality, endorsed efforts to evaluate the city's potential to adopt solar systems at the buildings' roof level. 
Using an aerial photogrammetric flight with a $30 \mathrm{~cm}$ resolution and data on the city's cadastre, namely blocks and buildings vector information which allows extracting data solely for the buildings in the analysis area, it was possible to adopt the LIDAR - Light Detection and Ranging methodology to build a local Digital Surface Model. With this model it is possible to identify each roof's slope, compass orientation, shadowing effects from adjacent buildings and/or architectural obstacles and combine it with data diffuse and reflected irradiation, in order to assess each building's solar irradiation. The output for this work is presented in $\mathrm{kWh} / \mathrm{sqm}$, data upon which solar systems expected productivity can easily be assessed in order to have a first measure of estimated productivity per roof. One improvement to this methodology lies in the non-consideration of the building's structure and effective capacity to support the solar systems.
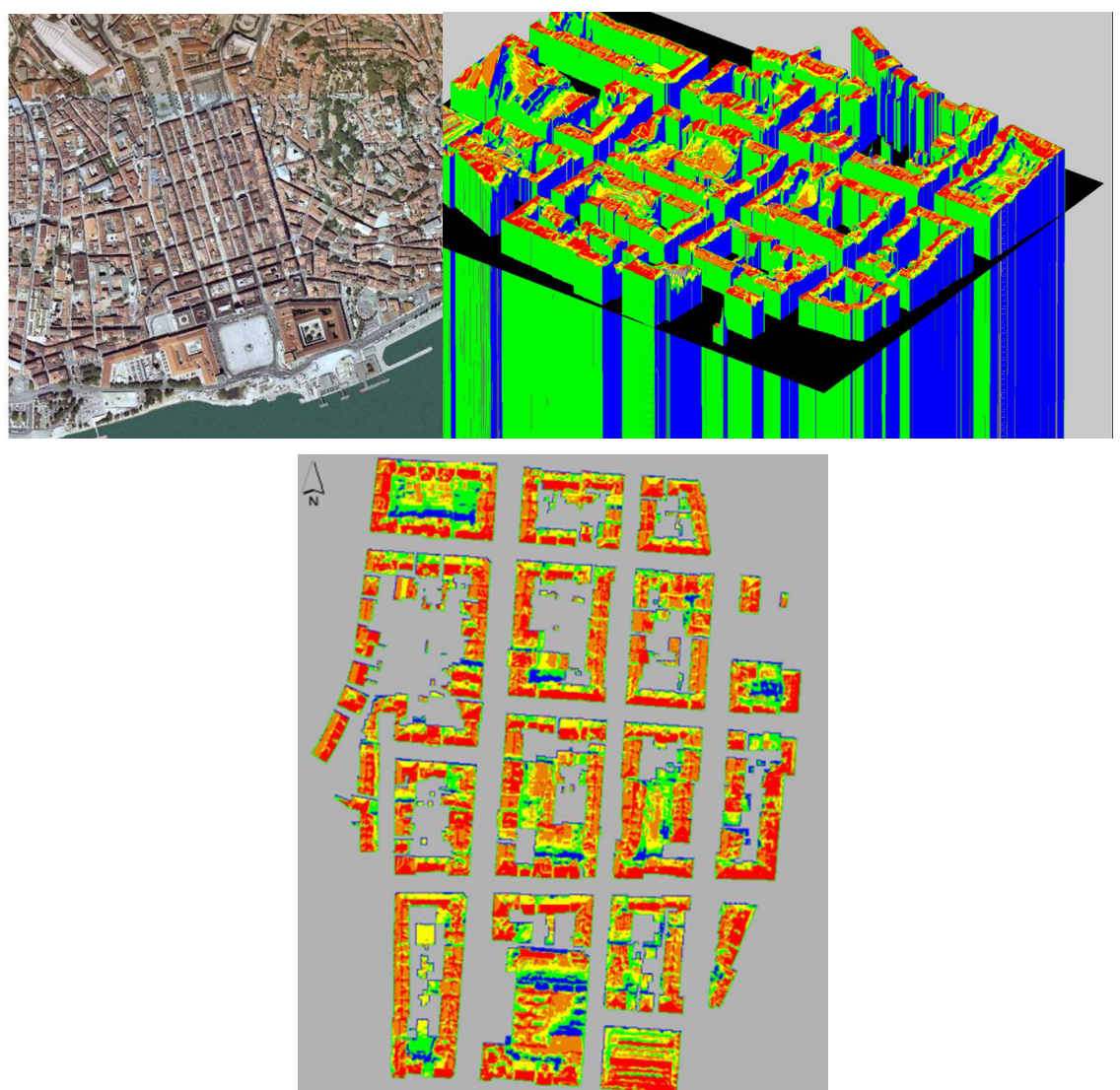

Figure 6: The Lisbon solar potential assessment methodology (aerial photo + digital surface model + solar potential).

This assessment of Lisbon's solar potential in its built patrimony is to serve as the basis to define Lisbon's strategy towards the adoption of solar technologies 
in the upcoming years, considering a top down approach (from technical to market potential) for both solar technologies, scenarios of different mixes between solar thermal and solar photovoltaic technologies and policy considerations within the European and national frameworks.

The implication of such a study will be used to develop scenarios, further exploited by introducing potential modifications to existing urban planning instruments. Special attention will be given to the instruments that are currently under revision, namely urban plans in new development areas.

\section{Conclusion}

Solar potential identification is a very useful tool for orientation of solar devices development in a city.

It is important to have in mind, before starting the study, the exact aim of it. There are 2 main objectives for solar potential identification and calculation:

- To guide the development of solar energy on a large scale (ex: city level) by identifying the urban areas where solar energy could be easily implemented or where energy needs are very high.

- To bring information to inhabitants and building owners on the potential of their roof to encourage them to invest in solar. Providing this information requires detailed calculations and results readily understandable by the beneficiaries. It is usually implemented at the level of a district previously identified.

In another hand, the different examples developed in this paper shows that there are still several methodologies used in Europe to identify and assess the potential. Most of the times, methodologies are constrained by the available input data for the study (GIS information, protected buildings heritage data, aerial photogrammetric flight...). Therefore, it is important to get in contact with the right stakeholders that can bring the necessary information.

\section{References}

[1] POLIS project: www.polis-solar.eu

[2] Project: Berlin Solar Potential Map: http://www.stadtentwicklung.berlin.de /umwelt/umweltatlas/ed806 04.htm

[3] Project: Sun Area Roof Cadastre: http://www.sun-area.net /index.php?id=103

[4] Project: Braunschweig Solar Potential Map: http://www.braunschweig.de /leben/umwelt naturschutz/klima/sun area/sunarea berechnungsdetails.html

[5] Google Sketchup: http://sketchup.google.com/intl/fr/

[6] Brito M., Gomes N., Santos T., Tenedório J., 2011. Photovoltaic potential in a Lisbon suburb using LiDAR data. Solar Energy 86 (2012) 283-288

[7] 2010, Baixa Pombalina solar potential map. Lisboa E-Nova

[8] "La integración de la generación energética distribuida en edificios existentes y su impacto estructural". 2009. M. Arroba Fernández and D. Mencías Carrizosa. I Congreso de Generación Distribuida - GENEDIS 2009. 